\title{
Sistem Pakar Mendiagnosa Penyakit Pencernaan Dengan Metode CaseBase Reasoning (Studi Kasus : RSUD Dr. H. Yuliddin Away)
}

\section{Article Info}

Article history:

Received Feb 26, 2020

Revised Mar 14, 2020

Accepted Apr 01, 2020

\section{Keywords:}

Digestive Disease, Case Base Reasoning, CBR, System Expert

\begin{abstract}
Digestive diseases are all diseases that occur in the channel digestion. This disease is a large group of diseases esophageal organs, stomach, duodenum first, second and third part, jejunum, ileum, colon, sigmoid colon, and rectum. Digestive disease need early prevention, in the field of computers how to anticipate can by using an expert system. Expert system is a system that can make conclusions like an expert. Expert systems have many one method is the CBR method. CBR method is a method inference based on the old case. This method can be applied in fields health and is widely implemented in the world of health one to diagnose various digestive diseases. System can do Diagnosis of the disease is based on the symptoms entered by the patient through questions the questions raised by the system and provide information about the illness suffered by the patient.
\end{abstract}

This is an open access article under the CC BY-SA license.

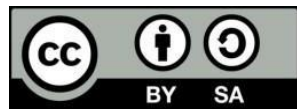

\section{Corresponding Author:}

Ilham Safar ${ }^{1}$, Aria Satria ${ }^{2}$

Politeknik Negeri Lhokseumawe ${ }^{1}$, Univeristas Ubudiyah Indonesia ${ }^{2}$

Email Address: 1ham_safar@pnl.ac.id ${ }^{1}$, aria_satria33@gmail.com²

(C) 2020 The Author: Published by. Cattleya Darmaya Fortuna

\section{Pendahuluan}

Penyakit pencernaan adalah semua penyakit yang terjadi pada saluran pencernaan [1]. Penyakit ini merupakan golongan besar dari penyakit pada organ esofagus, lambung, duodenum bagian pertama, kedua dan ketiga, jejunum, ileum, kolon, kolon sigmoid, dan rektum [2]. Penderita dapat mengalami gangguan pencernaan walaupun penyebab dan mekanisme terjadinya gangguan tersebut secara pasti belum diketahui, namun gangguan tersebut sangat dipengaruhi oleh faktor psikologis [3]. Faktor penyebab utama penyakit gangguan pencernaan disebabkan oleh makanan yang kurang baik dari segi kebersihan dan Kesehatan [4], keseimbangan nutrisi, pola makan yang kurang tepat, adanya infeksi, dan kelainan pada organ pencernaan sehingga akan terjangkit beberapa penyakit pencernaan seperti apendisitis, maag, tukak lambung, hepatitis, diare dan konstipasi [5]. Sistem pakar banyak diimplementasikan dalam dunia kesehatan untuk mendiagnosa berbagai penyakit. Pemanfaatan algoritma pemrograman komputer seperti PHP dan sebagainya serta didukung oleh inferensi engine seperti Case Based Reasoning (CBR) maka para pakar dapat digantikan untuk mendiagnosa penyakit dengan memanfaatkan basis pengetahuan pakar seperti gejala- gejala atau fakta mengenai suatu penyakit [6]. Diperlukan penanganan dini sebelum berkonsultasi secara khusus ke dokter spesialis penyakit pencernaan sebelum penyakit tersebut parah. Hal ini maka 
diperlukan adanya sebuah sistem yang dapat menggantikan dokter spesialis dalam mendiagnosa gejala awal penyakit pencernaan mengingat besarnya biaya konsultasi ke dokter. Sistem pakar diagnosa ini sangat dibutuhkan dalam mendiagnosa gejala dini penyebab-penyebab penyakit pencernaan. Sistem pakar mengandung pengetahuan tertentu sehingga setiap orang dapat menggunakannnya untuk memecahkan masalah yang bersifat spesifik [7]. Metode pengujian sistem yang digunakan adalah White Box Testing dan Black Box Testing [8]. Pengumpulan data yang dijadikan bahan pembuatan sistem pakar menggunakan metode case base reasoning ini dilakukan dengan wawancara [9]. Hasil pengujian CBR dengan cluster-indexing memiliki akurasi dan waktu proses yang lebih baik dari pada CBR non-indexing [10].

\section{Metode}

Pada penelitian ini menggunakan metode dan penerapan Penerapan model Case Based Reasoning (CBR) adalah [11]:

\section{Pengumpulan data}

Tahapan ini, peneliti mengumpulkan teori-teori yang berhubungan dengan perancangan sistem pakar mendiagnosa penyakit pencernaan [12]. Teori-teori tersebut dikumpulkan dari beberapa sumber seperti buku perpustakaan, artikel-artikel di internet serta referensi dari jurnal maupun artikel yang berkenaan dengan sistem pakardan metode CBR [13].

\section{Analisa dan perancangan(Analysis and Design)}

Pada tahapan ini penulis melakukan perancangan sebuah aplikasi web. Disini penulis merancang program agar user dapat melakukan diagnosa terhadap penyakit pencernaan. Langkah pertama dalam perancangan program ini adalah merancang proses kerja sistem dengan menggunakan sebuah use case yang menjelaskan secara rinci proses-proses yang akan dilakukan program dalam menghasilkan sebuah keputusan penyakit yang di derita.

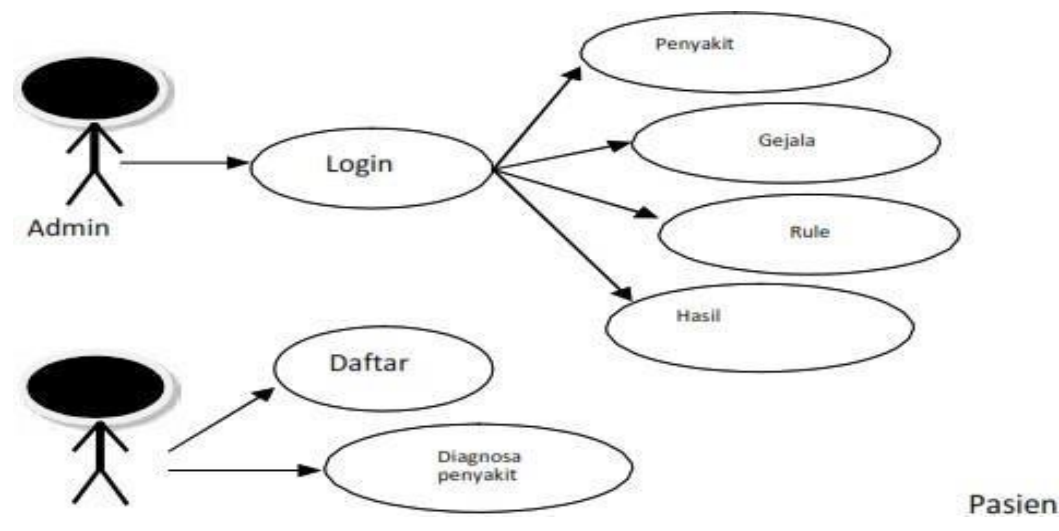

Gambar 1. Use Case Perancangan Sistem 


\section{Pengujian}

Tahapan akhir adalah melakukan pengujian atau testing program dalam hal ini peneliti melakukan serangkaian tes terhadap program yang telah dibuat. Tes program bertujuan untuk mendapatkan kesalahan-kesalahan (trouble) sehingga kesalahan dapat segera diperbaikisebelum launching program.

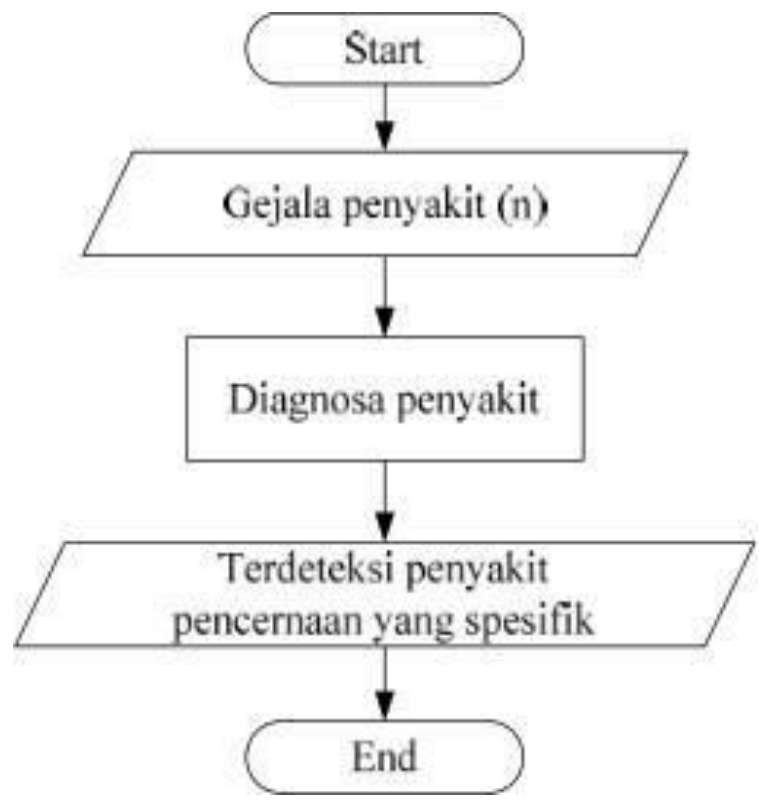

Gambar 2. Alur Pengujian Sistem

\section{Implementasi}

Setelah semua kebutuhan didapat, tahapan selanjutnya adalah mendeskripsikan aplikasi yang akan dikembangkan [14]. Pada penelitian ini akan dilakukukan perancangan dan pembangunan sistem dalam metode bentuk program aplikasi. Pada perancangan sistem akan digunakan metode Case Base Reasioning (CBR) sesuai dengan kebutuhan dalam penelitian ini [15].

\section{Analisa dan Pembahasan}

\section{Retrive Berdasarkan Kasus}

Pada saat terjadi permasalahan baru, pertama-tama sistem akan melakukan proses retrieve. Proses retrieve akan melakukan dua langkah pemrosesan, yaitu pengenalan masalah dan pencarian persamaan masalah pada database. Pada awal proses diagnosa pengguna akan menginputkan gejala-gejala yang dialaminya. Pengguna dapat menekan tombol 'lanjut' terus- menerus sampai pertanyaan parameter gejala yang terakhir atau jika pengguna merasa bahwa gejala yang dimasukan sudah cukup maka pengguna dapat menekan tombol 'proses' untuk dapat langsung mengetahui hasil diagnosanya. Kemudian sistem akan melakukan proses pembobotan dengan melakukan pencocokan satu per satu antara gejala yang dimasukan dengan data yang 
ada di dalam basis pengetahuan. Proses pembobotan ditampilkan dalam perhitungan di bawah ini.

Bobot parameter $(\mathrm{w})$ :

1. Gejala Penting $=5$

2. Gejala Sedang $=3$

3. Gejala Biasa $=1$

\section{Melakukan Proses Reuse}

Setelah proses retrieve selesai dilakukan, selanjutnya sistem akan melakukan proses reuse. Di dalam proses reuse, sistem akan menggunakan informasi permasalahan sebelumnya yang memiliki kesamaan untuk menyelesaikan permasalahan yang baru. Pada proses reuse akan menyalin, menyeleksi, dan melengkapi informasi yang akan digunakan.

\section{Melakukan Proses Revise}

Selanjutnya pada proses revise, informasi tersebut akan dikalkulasi, dievaluasi, dan diperbaiki kembali untuk mengatasi kesalahan-kesalahan yang terjadi pada permasalahan baru.

\section{Melakukan Proses Retain}

Pada proses terakhir, sistem akan melakukan proses retain. Proses retain akan mengindeks, mengintegrasi, dan mengekstrak solusi yang baru tersebut kedalam database. Selanjutnya, solusi baru itu akan disimpan ke dalam basis pengetahuan (knowledge-base) untuk menyelesaikan permasalahan yang akan datang. Tentunya, permasalahan yang akan diselesaikan adalah permasalahan yang memiliki kesamaan dengannya.

\section{Halaman Utama}

Tampilan halaman utama dari sistem pakar penyakit pencernaan menggunakan metode case base reasoning. Halaman utama atau halaman selamat datang merupakan halaman yang pertama tampil ketika pengguna mengakses halaman sistem pakar penyakit pencernaan. Halaman ini berisi menu diagnosa, Info Penyakit, About, Help dan Admin. Seperti gambar berikut:

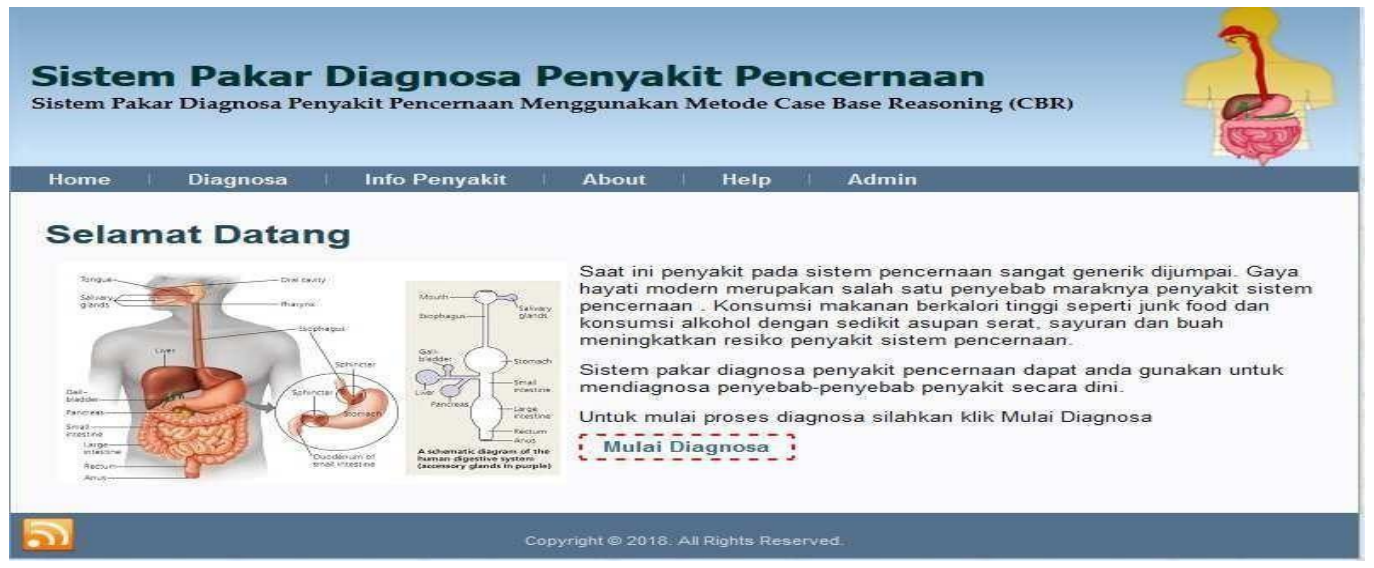

Gambar 3. Halaman Utama 


\section{Halaman Diagnostik}

Tampilan halaman diagnosa dari sistem pakar penyakit pencernaan menggunakan metode case base reasoning. Halaman diagnosa merupakan halaman yang akan tampil saat pasien memilih menu diagnosa. Halaman diagnosa berisi gejala-gejala penyakit pencernaan. Pasien memilih gejala-gejala yang dialami kemudian sistem akan menampilkan hasil diagnosa penyakit pencernaan dengan perhitungan metode case base reasoning. Seperti gambar berikut ini :

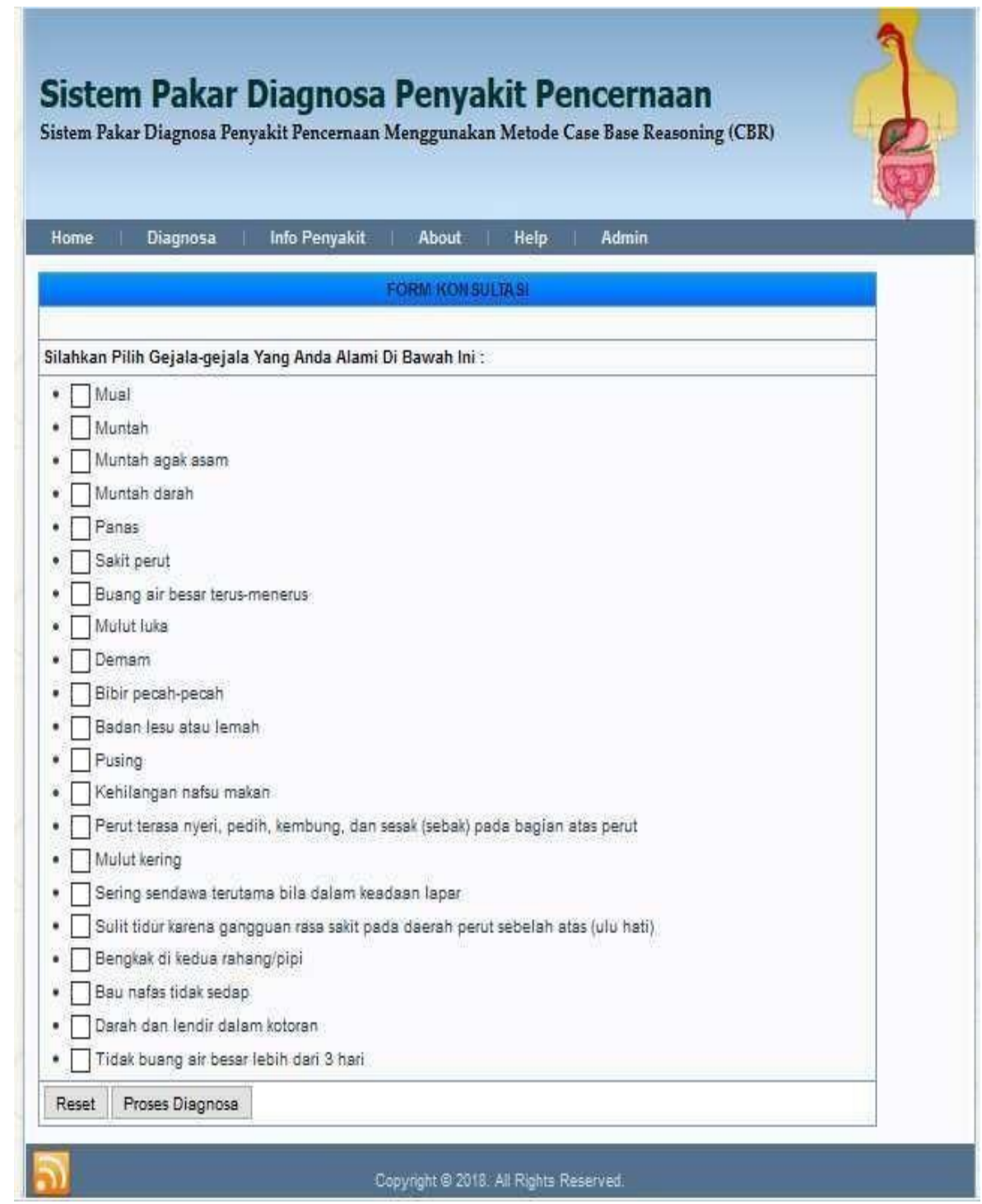

Gambar 4. Halaman Diagnostik

\section{Halaman Hasil Diagnosa}

Tampilan halaman hasil diagnosa dari sistem pakar penyakit pencernaan menggunakan metode case base reasoning. Halaman hasil diagnosa merupakan halaman yang akan tampil saat pasien telah selesai melakukan diagnosa. Halaman hasil diagnosa berisi tentang prediksi/kemungkinan jenis penyakit yang di derita oleh pasien dan solusi pengobatan dari penyakit tersebut. Pada halaman hasil diagnosa ada menu ulang 
diagnosa dan keluar diagnosa, apabila di pilih ulang diagnosa, pasien bisa mengulang kembali diagnosa, dan apabila di pilih keluar diagnosa, maka sistem akan mengarahkan ke registrasi pasien dan keluar dari diagnosa.

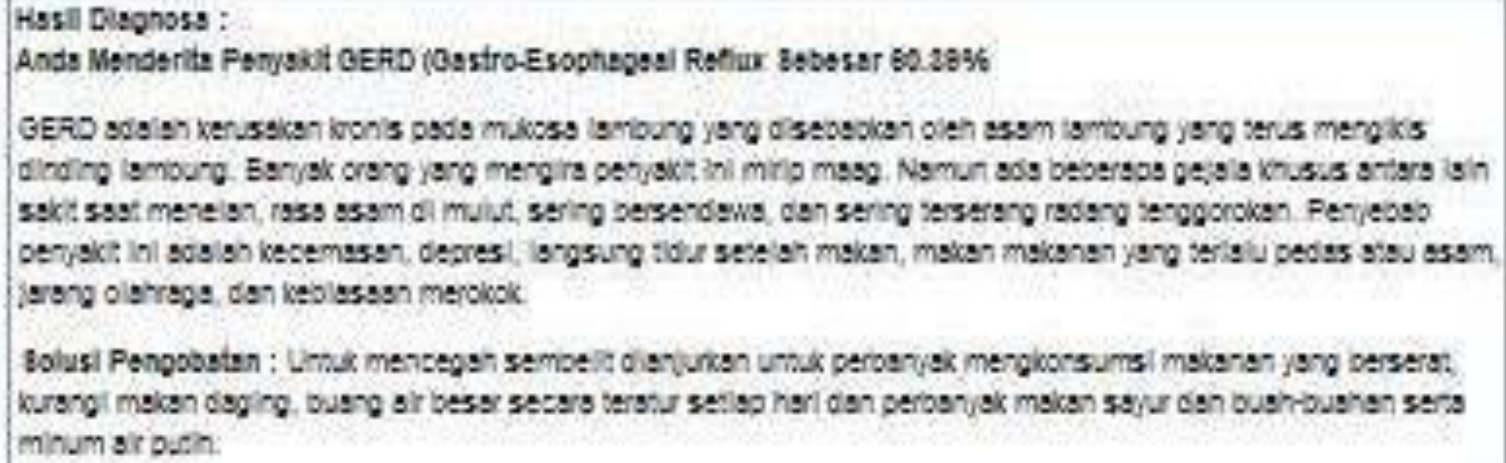

Gambar 5. Hasil Diagnosa

\section{Halaman Admin Laporan Gejala}

Halaman ini berfungsi untuk melihat gejala dari suatu penyakit pencernaan pada sistem. Sistem akan meminta admin untuk memilih nama penyakit dan sistem akan menampilkan laporan gejala-gejala penyakit berdasarkan penyakitnya. Seperti gambar berikut :

Daftar Gejala Per Penyakit
\begin{tabular}{|c|l|l|l|}
\hline No & Kode & Nama Gejala \\
\hline 1 & G009 & Demam \\
\hline 2 & G013 & Kehilangan nafsu makan & \\
\hline 3 & G018 & Bengkak di kedua rahang/pipi & Kembali \\
\hline
\end{tabular}

Gambar 6. Halaman Laporan Gejala

\section{Kesimpulan}

Berdasarkan hasil perancangan dan pembahasan pada perancangan sistem pakar diagnosa penyakit pencernaan maka dapat disimpulkan beberapa hal antara lain sebagai berikut : Aplikasi diagnosa penyakit pencernaan merupakan sebuah sarana penyedia informasi yang dapat memberikan informasi penyakit yang terdapat pada pencernaan manusia, yaitu parotitis, xerostomia, appendisitis, tukak lambung, diare, dan konstipasi. Sistem dapat melakukan diagnosa penyakit berdasarkan gejala-gejala yang diinputkan oleh pasien melalui pertanyaan gejala yang diajukan oleh sistem. Sistem dapat memberikan informasi mengenai penyakit yang diderita oleh pasien serta sistem dapat memberikan solusi untuk penanganan penyakit tersebut. Sistem yang berbasis web dapat digunakan bagi siapa saja yang menggunakannya dimana pun dan kapanpun tanpa ketergantungan dokter spesialis penyakit pencernaan. Semakin spesifik cirri-ciri gejala penyakit pencernaan maka akan semakin besar persentasekemungkinan terdeteksi jenis 
penyakit pencernaan yang lebih spesifik. Persentase penggunaan aplikasi systempakar ini $55 \%$ pengguna memahami alurpenggunaan dan telah melakukan dianogsa.

\section{Referensi}

[1] N. A. Latif, "Penerapan Model Decision Tree Algoritma Untuk Mengidentifikasi Penyakit Pencernaan Dengan Pengobatan Herbal," J. Ilmu Komput., vol. 5, no. Vol 5 No 2 (2019): Edisi September, 2019.

[2] E. Rahmanita, W. Agustiono, and R. Juliyanti, "SISTEM PAKAR DIAGNOSA PENYAKIT SALURAN PENCERNAAN DENGAN PERBANDINGAN METODE FORWARD CHAINING DAN DEMPSTER SHAFER," J. Simantec, vol. 7, no. 2, 2019, doi: 10.21107/simantec.v7i2.6743.

[3] A. Setiadi, Y. Yunita, and I. P. Nugroho, "APLIKASI SISTEM PAKAR DIAGNOSA PENYAKIT LAMBUNG MENGGUNAKAN FORWARD CHAINING," J. Pendidik. Inform. dan Sains, vol. 8, no. 1, 2019, doi: 10.31571/saintek.v8i1.1034.

[4] S. Murni and F. Riandari, "Penerapan Metode Teorema Bayes Pada Sistem Pakar Untuk Mendiagnosa Penyakit Lambung," J. Teknol. dan Ilmu Komput. Prima, vol. 1, no. 2, 2018, doi: 10.34012/jutikomp.v1i2.226.

[5] H. Kastubi, B. H. Subagyo, P. Keperawatan, S. Poltekkes, and K. Surabaya, "Faktor Dominan Yang Mempengaruhi Penurunan Nafsu Makan Pada Pasien Gastritis," J. Penelit. Kesehat., 2018.

[6] N. B. Riyanto and O. Suria, "Sistem Pakar Diagnosa Penyakit Pencernaan Menggunakan Metode Teorema Bayes," JMAI (Jurnal Multimed. Artif. Intell., vol. 2, no. 1, 2018, doi: 10.26486/jmai.v2i1.65.

[7] . S. and Y. R. T. Rianti, "Sistem Pakar Untuk Mendiagnosa Gangguan Pencernaan Pada Anak Dengan Metode Forward Chaining," JSiI (Jurnal Sist. Informasi), vol. 2, 2017, doi: 10.30656/jsii.v2i0.62.

[8] R. Sulaehani, "SISTEM PAKAR DIAGNOSA PENYAKIT TANAMAN KAKAO MENGGUNAKAN METODE CASE BASE REASONING (CBR) PADA KELOMPOK TANI GAPOKTAN DESA MAKARTI JAYA," Simtek J. Sist. Inf. dan Tek. Komput., vol. 4, no. 1, 2019, doi: 10.51876/simtek.v4i1.51.

[9] Z. Achmad Faisal, "SISTEM PAKAR DIAGNOSA PENYAKIT AYAM PETELUR MENGGUNAKAN METODE CASE BASED REASONING BERBASIS WEB," JATI (Jurnal Mhs. Tek. Inform., vol. 3, no. 2, 2019, doi: 10.36040/jati.v3i2.882.

[10] H. Santoso, "Case Base Reasoning Untuk Mendiagnosis Penyakit Hipertensi Menggunakan Metode Indexing Density Based Spatial Clustering Application With Noise (DBSCAN)," ETHOS (Jurnal Penelit. dan Pengabdian), vol. 7, no. 1, 2019, doi: 10.29313/ethos.v7i1.4206.

[11] S. Sadek and U. Usman, "SISTEM PAKAR DIAGNOSA PENYAKIT PERNAFASAN MENGGUNAKAN METODE CASE BASED REASIONING," $J$. Ipteks Terap., 2017, doi: 10.22216/jit.2017.v11i3.1034.

[12] R. M. Gozzal and D. Indarti, "Aplikasi Sistem Pakar Diagnosa Penyakit Pencernaan Balita dengan Metode Forward Chaining Berbasis Android Reynaldo," J. Ilm. Inform. Komput. Univ. Gunadarma, vol. 22, no. 3, 2017.

[13] Ashari and A. Y. Muniar, "Penerapan Sistem Pakar Untuk Mendiagnosa Penyakit 
Pencernaan Dengan Pengobatan Bahan Alami," Semin. Nas. Sains dan Teknol. 2016, no. November, 2016.

[14] N. L. P. Merawati and S. Hartati, "SISTEM REKOMENDASI TOPIK SKRIPSI MENGGUNAKAN METODE CASE BASED REASONING," J. Ilm. Teknol. Infomasi Terap., vol. 4, no. 3, 2018, doi: 10.33197/jitter.vol4.iss3.2018.164.

[15] F. Fatmayati, - Kusrini, and E. T. Lutfi, "Implementasi Case Base Reasoning Untuk Mendiagnosa Penyakit Gigi dan Mulut," Techno.Com, vol. 16, no. 1, 2017, doi: 10.33633/tc.v16i1.1331. 